\title{
Neural Stem Cells Improve Learning and Memory in Rats with Alzheimer's Disease
}

\author{
Shuliang $\mathrm{Wu}^{\mathrm{a}}$ Akira Sasaki $^{\mathrm{a}}$ Reiko Yoshimoto ${ }^{\mathrm{a}}$ Yumi Kawahara, ${ }^{\mathrm{a}} \mathrm{c}$ \\ Tomotaka Manabe $^{a}$ Katsuko Kataoka ${ }^{b}$ Makoto Asashima ${ }^{d}$ Louis Yuge ${ }^{a, c}$ \\ ${ }^{a}$ Division of Bio-Environmental Adaptation Sciences, Graduate School of Health Sciences, ${ }^{b}$ Department of \\ Histology and Cell Biology, Graduate School of Biomedical Sciences, and 'Space Bio-Laboratories Y.K., Hiroshima \\ University, Hiroshima; ${ }^{\mathrm{d}}$ Department of Life Sciences, Graduate School of Arts and Sciences and International \\ Cooperative Research Project (ICORP), Japan Science and Technology Corporation (JST), The University of Tokyo, \\ Tokyo, Japan
}

\section{Key Words}

Alzheimer's disease $\cdot$ Neural stem cells $\cdot$ Nerve growth

factor $\cdot$ Recombination adeno-associated virus

\begin{abstract}
Objective: We investigated whether neural stem cells (NSC) with transgenic expression of human nerve growth factor (hNGF) transplanted into the brain could offer a therapeutic option for the treatment of Alzheimer's disease (AD). Methods: We infused okadaic acid into rat lateral ventricles to establish a chronic AD animal model. In addition, NSC were stably transduced with $h N G F$ and enhanced green fluorescent protein (eGFP) genes (NSC-hNGF-eGFP) by using a recombination adeno-associated virus serotype 2 (rAAV2) vector. These genetically modified stem cells were grafted into the cerebral cortex of AD rats. Results: AD model rats showed significant damage in learning and memory function, with the formation of senile plaques and neurofibrillary tangles in the cerebral cortex. The transferred hNGF gene conferred stable and high levels of protein expression in NSC in vitro. Moreover, the NSC-hNGF-eGFP, but not the NSC, survived, integrating into the host brain and enhancing cognitive performance after transplantation. Conclusion: The injection of okadaic acid into rat lateral ventricles constitutes a promis-
\end{abstract}

ing animal model for investigating selective aspects of $A D$. rAAV2-mediated $h N G F$ delivery can render long-term and stable transduction of hNGF in NSC. NSC-hNGF-eGFP transplantation may offer a viable therapeutic approach for treatment of AD.

Copyright $\odot 2008$ S. Karger AG, Basel

\section{Introduction}

Alzheimer's disease (AD) is one of the most common neurodegenerative dementias, affecting more than 12 million people worldwide $[1,2]$. The average survival from diagnosis is approximately 8 years. Symptoms of the disease include progressive impairments in learning and memory [3-5], and hallmark neuropathologic features of AD include depositions of extracellular senile plaques (SP), the formation of intracellular neurofibrillary tangles (NFT), and widespread neurodegeneration [6-9]. SP primarily comprise amyloid $\beta$-peptide $(A \beta)$, which is generated from amyloid precursor protein (APP) [10, 11]. NFT are composed largely of hyperphosphorylated $\tau$ protein $[12,13]$. Abnormal $\tau$ phosphorylation may cause NFT formation and cytoskeletal disruption, possibly leading to neuronal malfunction and death [14-16]. No

\section{KARGER}

Fax +4161306 1234 E-Mail karger@karger.ch www.karger.com

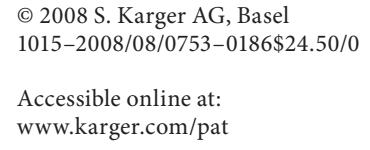

Dr. Louis Yuge

Division of Bio-Environmental Adaptation Sciences

Graduate School of Health Sciences, Hiroshima University

1-2-3 Kasumi, Minami-ku, Hiroshima 734-8551 (Japan)

Tel. +81 82257 5425, Fax +81 82257 5429, E-Mail ryuge@hiroshima-u.ac.jp 
proven medical therapy is available to mitigate the devastating clinical manifestations of AD.

Neural stem cells (NSC) are undifferentiated cells capable of self-renewal or differentiation [17-19]. Recently, the transplantation of NSC has been proposed. This option might represent a plausible future therapy for $\mathrm{AD}$, to provide unlimited stem cell numbers in vitro, stably express transgenes, release therapeutically active substances to maintain neuronal function, prevent the progressive loss of neurons, and induce regenerative responses in neurons [20-22]. Transplantation of NSC-GDNF (glial cell line-derived neurotrophic factor) into an animal model of Parkinson's disease prevented the degeneration of dopaminergic neurons in the substantia nigra, and resulted in limited functional recovery of the animals $[23$, 24].

This study examined (1) whether rAAV2 can maintain stable and high-level human nerve growth factor ( $h N G F$ ) and enhanced green fluorescent protein $(e G F P)$ transgene expression in NSC and (2) whether genetically modified NSC- $h N G F-e G F P$ engraft well in the host brain and bring about functional effects, such as recovery from learning and memory impairments in $\mathrm{AD}$ rats. Our results indicated that $\mathrm{AAAV} 2$ vectors maintain high-level transgene expression in NSC, and that overexpression of $h N G F$ in this way significantly improves learning and memory in $\mathrm{AD}$ rats.

\section{Materials and Methods}

\section{Animals}

Male Wistar rats (270-290 g body weight) and embryonic day 17 (E17) Wistar rat fetuses were used in this study. All rats were maintained in a temperature-controlled environment of $24 \pm$ $1{ }^{\circ} \mathrm{C}$ with a 12-hour dark/light cycle (dark cycle: 8:00 p.m. to 8:00 a.m.) with food and water supplied ad libitum throughout the experiments. All experimental protocols accorded with the Guidelines of Animal Use and Care of Hiroshima University.

\section{Neural Stem Cell Culture}

The forebrain cerebral cortex including the subventricular zones and the hippocampus was removed from E17 rat fetuses. After removal of the meninges, the tissue was minced and then digested in $0.25 \%$ trypsin solution with $0.1 \mathrm{~mm}$ EDTA at room temperature for $15 \mathrm{~min}$. Following trituration through a plastic 5-ml pipette and a fire-polished Pasteur pipette, the dissociate was filtered through sterile gauze, washed twice in $5 \mathrm{ml}$ of a 1:1 mixture of Dulbecco's modified Eagle's medium (DMEM) and Ham's F-12 medium (DMEM/F12; Invitrogen, Carlsbad, Calif., USA) to eliminate cell aggregates and debris. Cells were then counted with a hemocytometer. Finally, the cells were resuspended in DMEM/F12 containing $20 \mathrm{ng} / \mathrm{ml}$ epidermal growth factor (EGF; Sigma, St. Louis, Mo., USA), $20 \mathrm{ng} / \mathrm{ml}$ basic fibroblast growth factor (Sigma), and B-27 growth medium (Sigma). The resulting cell suspension was plated onto poly-L-lysine (Sigma)coated T-75 culture flasks (Iwaki, Tokyo, Japan) at a density of $5 \times 10^{4} \mathrm{cells} / \mathrm{ml}$. Neurosphere cultures were maintained at $37^{\circ} \mathrm{C}$ in an incubator with $5 \% \mathrm{CO}_{2}$ and $95 \%$ humidity.

\section{rAAV2 Vector Production}

rAAV2 vectors were prepared as described previously [25]. The rAAV2 vector contains inverted terminal repeats flanking a transcription unit containing $h N G F$ and $e G F P$ cDNA driven by a cytomegalovirus promoter. The vector plasmid was packaged into the rAAV2 capsid using the AAVMax ${ }^{\mathrm{TM}}$ package system in a baby hamster kidney (BHK-21) cell line. Briefly, a recombinant herpes simplex virus type 1 (HSV1-rc/ $\left./{ }^{\Delta} \mathrm{UL} 2\right)$, which is able to express adeno-associated virus Rep and Cap proteins, was used for rAAV2 replication and packaging. The rAAV2 proviral cell line (BHK/SG2) with $h N G F$ and $e G F P$ gene expression cassette inserted was established by transfecting BHK-21 cells with rAAV2 vector plasmid pSNAV-2-hNGF-eGFP. The BHK/SG2 cells were infected with HSV1-rc/ ${ }^{\Delta}$ UL2 to generate rAAV2 vectors. The cells were harvested, lysed by 3 freeze/thaw cycles, and the virions isolated by cesium chloride gradient centrifugation. The gradient fractions containing rAAV2 were dialyzed against sterile PBS, and stored at $-80^{\circ} \mathrm{C}$. Dot blot analysis demonstrated particle titers of $1 \times 10^{12}$ virus genome $/ \mathrm{ml}$.

\section{Transfection of rAAV2-hNGF-eGFP Viruses into NSC}

For transfection experiments, $1 \times 10^{6}$ NSC were plated on 96well plates in DMEM/F12 medium (as described above). Twentyfour hours after seeding, different multiplicity of infections (MOI) of the rAAV2- $h N G F-e G F P$ virus $\left(2 \times 10^{4}, 1 \times 10^{4}\right.$ and $\left.5 \times 10^{4}\right)$ were added to the cell cultures. After $96 \mathrm{~h}$, the culture supernatant was replaced with medium containing EGF and bFGF, and supplemented with B-27 growth medium.

Surgical Procedures

Rats were anesthetized with $50 \mathrm{mg} / \mathrm{kg}$ sodium pentobarbital, and placed in a stereotaxic apparatus (Narishige, Tokyo, Japan) according to the brain atlas of Paxinos and Watson [26]. Unilateral cannulas (model 2004; Alzet, Cupertino, Calif., USA) were implanted into the right lateral ventricle (coordinates: $0.8 \mathrm{~mm}$ posterior to the bregma, $1.3 \mathrm{~mm}$ right lateral to the midline, and $4.0 \mathrm{~mm}$ ventral to the skull surface). The cannulas were fixed to the skull with dental cement, and connected to the pump end with sterile, coiled polyethylene tubing. The pump was placed subcutaneously in the neck/shoulder area. Rats received an intramuscular injection of penicillin $(20,000 \mathrm{U})$ into each thigh after the surgery and were given water with acetaminophen $(0.35 \mathrm{mg} / \mathrm{ml})$ for 3 days.

On day 0,36 rats of the okadaic acid (OA)-treated group were intracerebroventricularly infused with OA (80 $\mu \mathrm{g} /$ day, Sigma), dissolved in $0.1 \mathrm{M}$ phosphate-buffered artificial cerebrospinal fluid (CSF). Artificial CSF rats $(\mathrm{n}=36)$ were intracerebroventricularly infused with artificial CSF. The sham operation rats $(n=36)$ received no infusion. The Alzet osmotic pumps (lifespan 28 days) were changed on day 28 . On day 56 , the pump and tubing were removed from the anesthetized rats. To confirm the OA dosage administered, the total infusion volume was determined for each animal. The rats were allowed to rest for 1 week, and the testing phases of learning, memory, and the exploratory task were performed as follows. 


\section{Morris Water Maze Test}

The spatial learning and memory ability of rats was assessed in the Morris water maze [27]. The water maze $(180 \mathrm{~cm}$ in diameter, $60 \mathrm{~cm}$ in height) was located in an experimental room rich in extra-maze cues and was filled with water $\left(25^{\circ} \mathrm{C}\right)$ made opaque by white nontoxic tempera paint. An escape platform was hidden $1.5 \mathrm{~cm}$ below the water surface in a fixed location in one quadrant of the maze. Rats received 5 trials per day with 120 -second intervals. On day 0 , rats were allowed to swim freely for $120 \mathrm{~s}$ without a platform to acclimatize to the pool. On days 1-4, rats were trained to locate and escape onto the submerged platform from random release points around the pool. If an animal did not find the platform in $120 \mathrm{~s}$, it was placed on the platform for $10 \mathrm{~s}$ and then returned to the home cage. The time to reach the platform (escape latency) was measured with a computerized tracking system (Etho Vision 2.0; Noldus Information Technology, Wageningen, The Netherlands). On day 5 , the platform was removed, and a 120 -second probe trial was run to examine retention of spatial memory. The percentage of time spent in each quadrant was recorded. All experiments were conducted in a blinded manner.

\section{Open-Field Task}

Exploratory locomotion activity was assessed by open-field testing. The apparatus consisted of a gray box open at the top and measuring $50 \mathrm{~cm}$ long $\times 30 \mathrm{~cm}$ wide $\times 20 \mathrm{~cm}$ high. The floor was divided into fifteen $10-\mathrm{cm}$ squares. The testing took place under normal room illumination. Each rat was placed randomly in one corner of the box. The behavior was videotaped for $5 \mathrm{~min}$. The following measurements were taken: number of squares entered (all 4 paws inside the square), time spent in the corner (the time spent in the 4 corner squares), and time spent rearing (an animal standing on its hind legs with forelegs in the air or against the wall). After each rat had been tested, the box was thoroughly cleaned to remove odor cues.

\section{Histology}

After deep anesthesia, animals were perfused intracardially with saline $(0.5 \%)$, followed by $4 \%$ paraformaldehyde. The brains were then removed and fixed in paraformaldehyde for $24 \mathrm{~h}$, and subsequently transferred to $30 \%$ sucrose at least 4 days before sectioning. Sections of $40-100 \mu \mathrm{m}$ in thickness were cut on a cryostat microtome and processed for thioflavin-S fluorescence [28] and Bielschowsky silver staining [29].

\section{Transplantation}

Transplanted cells were mildly trypsinized into single cells in $0.1 \mathrm{M}$ phosphate-buffered saline (PBS). Cell viability was checked by trypan blue exclusion. The total number of cells was determined using a hemocytometer. The cells were centrifuged at $1,000 \mathrm{rpm}$ for $5 \mathrm{~min}$, and resuspended to produce a final concentration of $2 \times 10^{4}$ cells $/ \mathrm{ml}$. AD rats were anesthetized and placed under the stereotaxic instrument. The cells were loaded into a 5 - $\mu$ l Hamilton syringe held in a micromanipulator (MP-85, Sutter Instruments, Novato, Calif., USA) for transplantation. The NSC$h N G F-e G F P$ rats $(\mathrm{n}=12)$ were injected bilaterally with a 5 - $\mu \mathrm{l}$ NSC-hNGF-eGFP suspension into the hippocampus and cerebral cortex of AD rats ( $5 \mu \mathrm{l} /$ injection site/unilateral). NSC rats $(n=12)$ were injected with the same quantities of NSC suspension at the same sites. The other 12 rats were injected with the same quantities of culture medium at the same sites (medium group). Trans- plantation coordinates for the hippocampus, relative to bregma (AP), the midline (ML), and the dura-ventral (DV) were $1.2 \mathrm{~mm}$ (ML), $1.7 \mathrm{~mm}$ (AP), and $3.5 \mathrm{~mm}$ (DV) for the hippocampus, and $2.0 \mathrm{~mm} \mathrm{ML}, 2.0 \mathrm{~mm} \mathrm{AP}$, and $3.0 \mathrm{~mm} \mathrm{DV}$ for the cerebral cortex. A 1- $\mu$ l cell suspension was injected over a period of 15-20 s into the transplantation site, and the needle was left in position for a further $5 \mathrm{~s}$ before being slowly withdrawn.

\section{Immunofluorescence Staining}

The cultured NSC were fixed with $4 \%$ formaldehyde for $10 \mathrm{~min}$ at room temperature. After 3 washes with PBS for 5 min each, the cells were incubated for $2 \mathrm{~h}$ at room temperature with blocking buffer (DMEM, 0.1\% glycine, $0.1 \%$ lysine, $5 \%$ FBS, and $0.2 \%$ Triton $\mathrm{X}-100)$. Primary antibody against nestin (mouse monoclonal IgG, 1:100; Chemicon, El Segundo, Calif., USA) was diluted in blocking buffer and incubated overnight at $4^{\circ} \mathrm{C}$. After 3 washes with PBS for $5 \mathrm{~min}$ each, the cells were incubated for $1 \mathrm{~h}$ at room temperature with goat anti-mouse IgG Alexa Fluor 488 conjugate (1:200; Invitrogen) diluted in blocking buffer without Triton X100. Samples were then washed 3 times with PBS. Fluorescence was detected using an inverted fluorescence microscope (Eclipse 300E; Nikon, Düsseldorf, Germany), and digital images were captured with a 12-bit digital CCD camera (Visicam; Visitron, $\mathrm{Mu}$ nich, Germany).

\section{Statistical Analysis}

Results were presented as means \pm SEM. The data were analyzed using 1-way or 2-way analysis of variance (ANOVA) followed by the Newman-Keuls multiple range test. Repeated measures were also used when necessary. A statistical difference was accepted at a 5\% level, unless indicated otherwise.

\section{Results}

\section{Overexpression of NSC-hNGF-eGFP}

NSC isolated from subventricular zones and the hippocampus of E17 rat fetuses could proliferate, self-renew and differentiate (fig. 1a-c). To select cells with the highest efficiency of $e G F P$ expression, 3 different MOI of rAAV2- $h N G F-e G F P$ virus were added in the cell suspension. MOI $\left(5 \times 10^{5}\right)$ of rAAV2- $h N G F-e G F P$ virus showed the highest transduction efficiency, with approximately $87 \%$ of cells infected by day 4 (fig. $1 \mathrm{~d}, \mathrm{e}, 2$ ).

\section{Behavioral Analyses}

To determine the effect of OA on learning and memory performance, all rat groups were tested in the Morris water maze and open-field task 63 days after surgery. The OA group spent a significantly longer time finding the hidden platform in the Morris water maze than the sham operation and artificial CSF groups ( $p<0.001$, fig. 3a). In the spatial probe trial, the OA group spent a significantly lower percentage of time in the target quadrant than rats in the sham operation and artificial CSF groups $(\mathrm{p}<$ 
Fig. 1. NSC were isolated from the subventicular zone and hippocampus. a The NSC colonies formed neurospheres by self-renewal. b Primary NSC began to differentiate when bFGF and EGF were removed. c Nestin, a NSC marker, was expressed in neurospheres by immunocytochemistry. d NSC began to express NGF and eGFP after $24 \mathrm{~h}$ of infection. e NSC showed higher expressions of NGF and eGFP $72 \mathrm{~h}$ after the infection. Images are representative of 4 independent experiments. Scale bars: $50 \mu \mathrm{m}$.
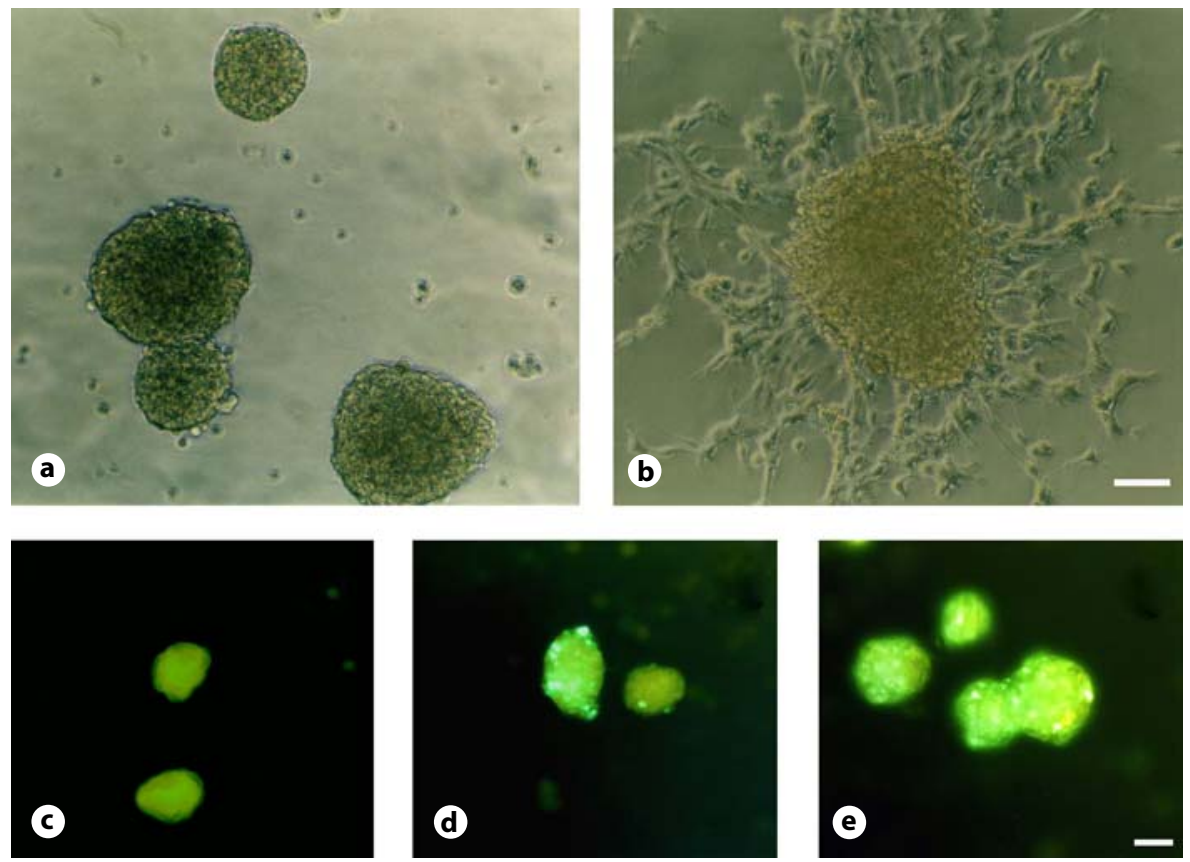

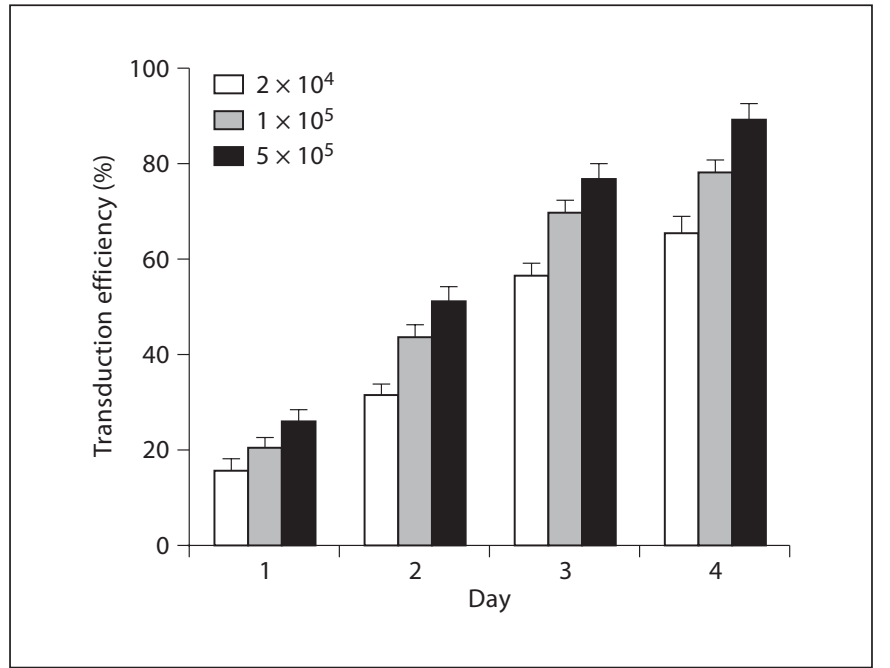

Fig. 2. The NSC were infected at different MOI of rAAV2-NGF$e G F P$ virus $\left(2 \times 10^{4}, 1 \times 10^{5}\right.$ and $\left.5 \times 10^{5}\right)$.

0.001, fig. 3b). The artificial CSF and sham operation groups showed similar behavior in the water maze task ( $p>0.05)$. Swimming speed was not affected by the treatment throughout the testing (data not shown), indicating that the water-maze differences were not due to motor deficits. In the open-field task, OA-treated rats exhibited lower levels of locomotion activity and spent less time in motion than the sham operation and artificial CSF groups $(\mathrm{p}<0.001)$. The OA group also showed maximal habituation to the novel environment, at which time the other 2 groups still showed minimal habituation. There were no differences between artificial CSF and sham operation groups ( $p>0.05$, fig. $4 a-c)$. These results suggest that spatial learning was significantly impaired in OA-treated rats.

The therapeutic effects of NSC- $h N G F-e G F P$ on learning and memory in $\mathrm{AD}$ model rats were tested in the Morris water maze and open-field task on day 30 after transplantation. The NSC-hNGF-eGFP group exhibited significant improvements in performance in both the water maze and open-field testing. The escape latency ability of NSC- $h N G F-e G F P$ rats was significantly different from that of the OA-, NSC-, and media-treated animals $(\mathrm{p}<0.001)$; there were no differences among these 3 groups ( $p>0.05$, fig. 3a). NSC-hNGF-eGFP rats spent more time in the target quadrant than those in the OA, NSC, and media groups (fig. 3b), and showed normal exploratory behavior in the open-field task (fig. $4 \mathrm{a}-\mathrm{c}$ ). There was a significant difference between the NSC-hNGF$e G F P$ and OA groups in locomotion activity $(\mathrm{p}<0.001)$, while the overall locomotion activities of the NSC- $h N G F-$ eGFP and sham operation groups were not statistically different in the open-field task (fig. 4a-c). Differences were apparent between the NSC and OA groups in locomotion activity, but were not statistically significant $(\mathrm{p}>$ 

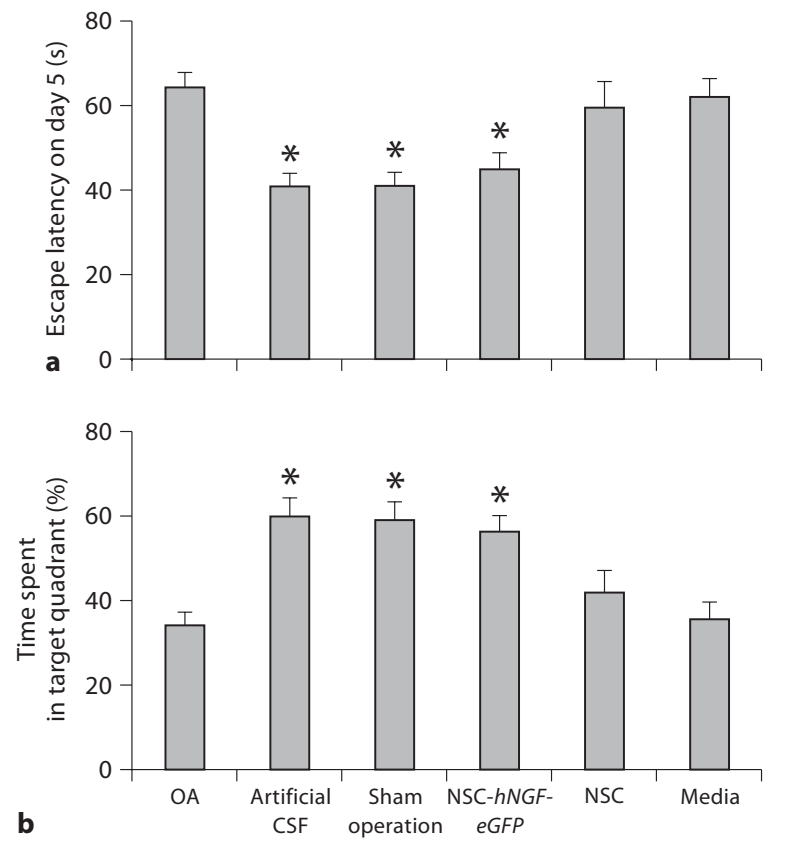

Fig. 3. Spatial learning was assessed by the Morris water maze test. a Time taken by rats to find the hidden platform on day 5 . b Time spent by rats in target quadrant during the spatial probe trial. Five trials were recorded following a 120 -second intertrial interval. ${ }^{*} \mathrm{p}<0.001$ compared to OA-treated rats.

0.05). Analyses of the Morris water maze and open-field task results revealed that OA causes severe damage to the learning, memory, and exploratory activity of rats, and NSC-hNGF-eGFP transplantation induced a significant improvement in learning, memory, and exploratory behavior.

\section{Histopathological Analyses}

OA effects on SP deposition and NFT formation were evaluated by thioflavin-S fluorescence staining and Bielschowsky silver staining, respectively. SP deposits and NFT were observed in the cortex of OA-treated rats, but not in the artificial CSF control or sham operation groups (fig. 5a-d).

We used $e G F P$ as a reporter gene to identify cellular transduction within the brain regions. We found that hNGF was expressed in different brain regions, and 30 days after transplantation, NSC-hNGF-eGFP were integrated into the surrounding host cells (fig. 6).
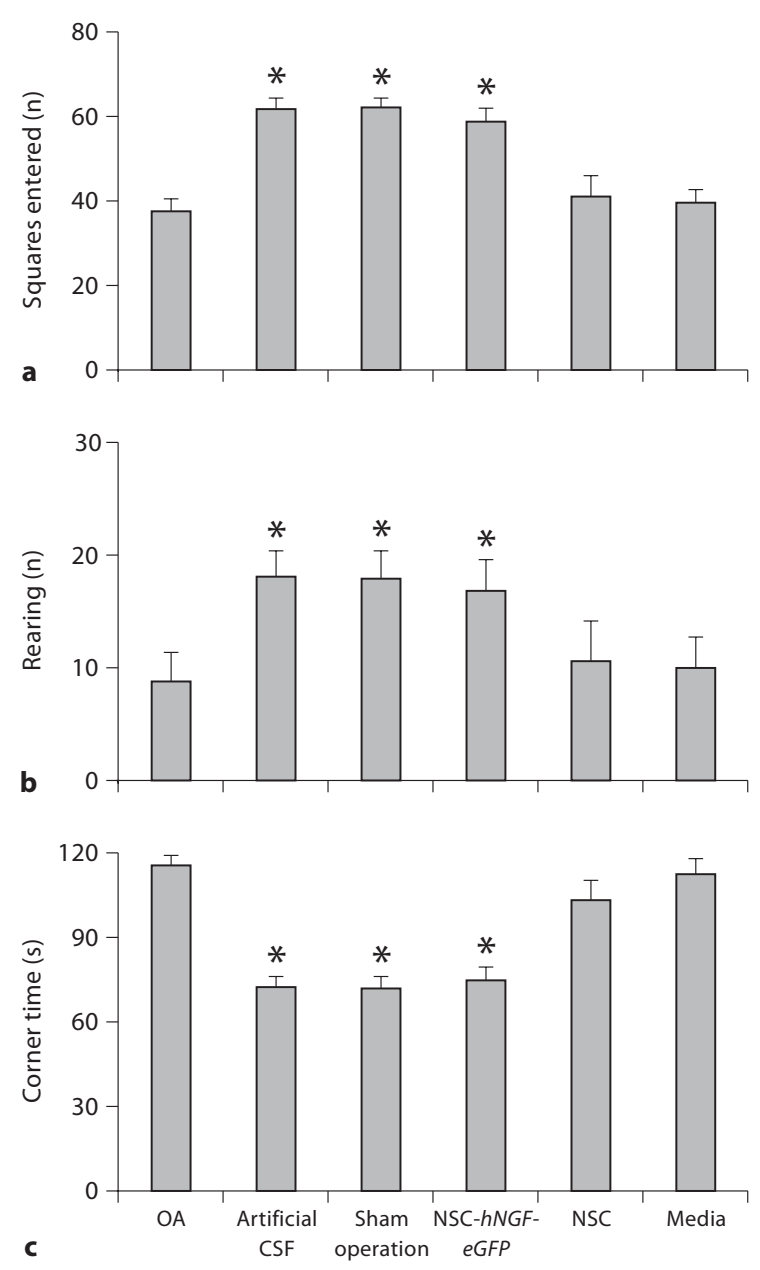

Fig. 4. Locomotion activity was assessed in the open-field task. a Number of squares entered within $5 \mathrm{~min}$. b Number of times rats reared within $5 \mathrm{~min}$. c Time spent in a corner within $5 \mathrm{~min}$. ${ }^{*} \mathrm{p}<0.001$ compared to the OA-treated rats.

\section{Discussion}

This study demonstrated that chronic infusion of serine/threonine protein phosphatase (PP) inhibitor, $\mathrm{OA}$, into rat lateral ventricles severely impairs learning, memory, and exploratory activity. In addition, SP deposition and NFT were formed in treated rat cortexes. We also demonstrated that the OA-induced neurological dysfunction was improved through the transplantation of NSC-hNGF-eGFP. Our results suggest a role for NSC$h N G F-e G F P$ in the treatment of AD. 

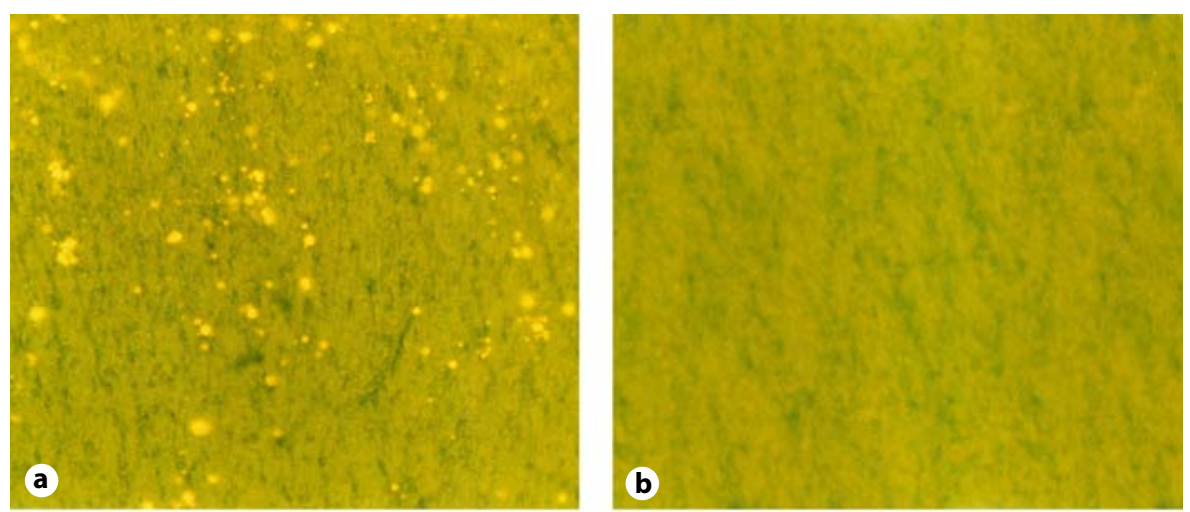

Fig. 5. SP deposition and NFT formation were detected by thioflavin-S fluorescence staining and Bielschowsky silver staining, respectively. a SP were detected in OAtreated rat cortex. b SP were not present in the cortex of control rats. c NFT accumulated in the cortex of OA-treated rats. d NFT were not detected in the control group. Scale bar: $50 \mu \mathrm{m}$.

Fig. 6. rAAV2-modified transgene expression was observed in different regions of the rat brains after transplantation. a NGF were expressed in cortex after 15 days. b NGF were expressed in hippocampus and NSC were integrated into host cells 30 days after transplantation. Scale bar: $50 \mu \mathrm{m}$.
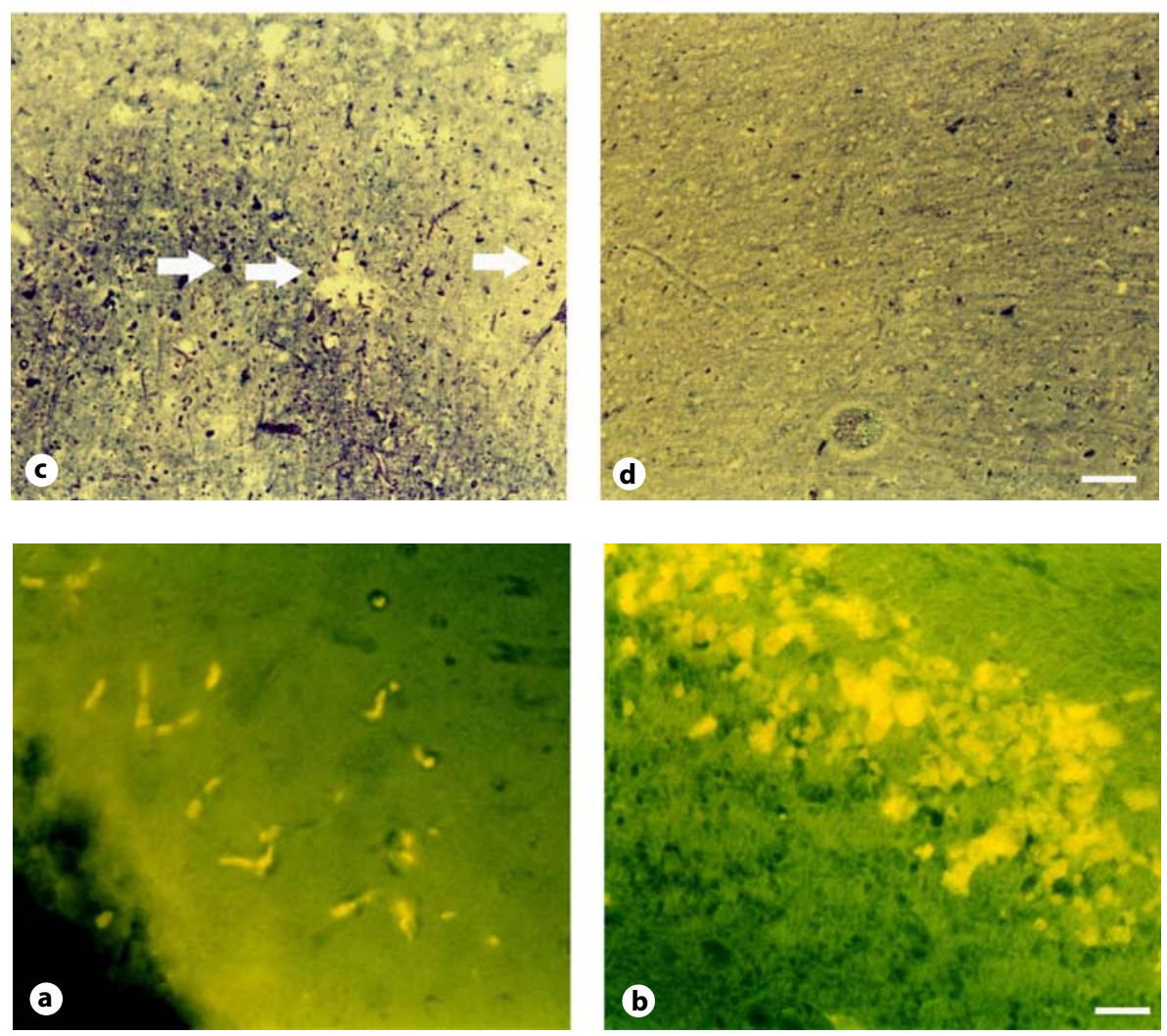

Protein phosphorylation and dephosphorylation play an important role in the regulation of $\mathrm{AD}$ pathogenesis [30-32]. In vitro, OA causes hyperphosphorylation of $\tau$, modification of synapse structure, and the destruction of stable microtubules. PP can restore the biological activity of abnormally phosphorylated $\tau$ in vitro [33], and a recent in vivo study found decreased PP2A activity and mRNA expression in AD brains [34], linking abnormalities in phosphatase activity and $\mathrm{AD}$ pathogenesis. Our current results strongly imply that $\mathrm{OA}$ acts by perturbing protein phosphorylation and dephosphorylation, which may in turn affect several pathological processes such as the deposition of $A \beta$, inflammatory responses, oxidative injury, neurotransmitter deficits, and neuronal apoptosis. Our results also suggested that stereotaxic and chronic infusion of OA into lateral ventricles of rats might provide a useful $A D$ animal model.

Neurotrophic factors have emerged recently as promising therapeutic tools for $\mathrm{AD}$ because they can prevent neuronal cell death [35-37]. A key to successful cell and gene therapy is the selection of appropriate therapeutic genes and the modes of molecular and cellular delivery 
of that gene. NGF is the archetypical protein discovered in the 1960s for increasing both survival and functioning of cholinergic neurons. However, the blood-brain barrier does not allow penetration of this protein into the brain in vivo [38]. Using gene therapy, growth factors can be delivered directly to the brain [39-41], and genetically modified NSC expressing hNGF and eGFP offer longterm therapeutic efficacy as a delivery vehicle to treat neurodegenerative diseases $[42,43]$. The transplantation of NSC-hNGF-eGFP into an experimental model of neural degenerative disease compensated for some deficits by releasing neurotrophic factors [36]. However, our knowledge of the mechanism of functional improvement in the AD model brain remains limited. The present study showed that NSC sustain their proliferation potential when cultured in DMEM/F12 (1:1) serum-free medium containing EGF and bFGF, which are both known to promote NSC proliferation $[44,45]$. To understand the nature of differentiation, we induced NSC to differentiate into neurons and glial cells in vitro. Consistent with previous studies, our results confirmed that these cells isolated from the embryonic fetus have differentiation potential. To obtain genetically modified NSC clones, we selected recombinant adeno-associated virus (rAAV2) vector to infect NSC in vitro. Our data indicated that rAAV2 can efficiently and stably infect NSC. These findings support the hypothesis that NSC are ideal therapeutic-gene vehicles.

The formation of $A \beta$ and the accumulation of NFT in the brain trigger the pathological cascade of $\mathrm{AD}$, including the degeneration of neuronal elements [46, 47]. Intravenously delivered NSC were recently suggested to reduce progressive $\mathrm{AD}[48,49]$, and transplantation studies using NSC have shown site-specific neuronal differentiation in neurogenesis sites of the adult brain [50]. NSC also show remarkable plasticity and an ability to respond to epigenetic signals in vivo by generating region-specific neurons [51-53]. In a different study, genetically modified NSC used for gene transfer by direct intracerebral injection of NGF promoted regeneration and reversed age-related atrophy of cholinergic neurons [54, 55]. In our study, NSC- $h N G F-e G F P$ transplanted into rat brain secreted hNGF, and integrated into the surrounding host tissue as well as improving neurological function. These genetically modified cells survived in the long term, without perturbing the recipient brain and without becoming tumorigenic or immunogenic. However, transplantation of NSC did not achieve similar results. One explanation for this finding is that the modified NSC$h N G F-e G F P$, but not unmodified NSC, survived and dif- ferentiated into functional neurons and secreted hNGF over a long time. Secreted hNGF could act to increase the number of NSC acting directly on the NSC themselves or acting indirectly through augmentation of the cholinergic system, or a combination of both, although further characterization would be necessary to confirm this proposal. Both NSC and NGF rescue damaged cholinergic neurons, prevent the progressive loss of neurons, induce additional regenerative responses in neurons such as increased neurotransmitter turnover, provide neurotrophic and neuroprotective support, and maintain neuronal function [56].

In summary, our results demonstrated that chronic infusion of $\mathrm{OA}$ into rat brain ventricles can partly mimic the clinical pathology of $\mathrm{AD}$, and that $\mathrm{rAAV} 2$ is a useful and efficient way to deliver $h N G F$ directly into the NSC. Furthermore, genetically modified NSC-hNGF-eGFP show remarkable capacity to integrate into host tissue, secrete neurotrophic factor over the long term, and replace damaged or lost neural cells. Thus, using genetically modified NSC-hNGF-eGFP to replace damaged or lost neurons and secrete neurotrophic factor is a potential new approach toward restoring function in AD. Further investigations are needed to determine the specific therapeutic effects and explore the underlying mechanism.

\section{Acknowledgements}

We thank all members of the Bio-Environmental Adaptation Sciences Division, Hiroshima University for their help and support during our research.

This study was supported by the Grants-in-Aid for Scientific Research (C), No. 10838021 and No. 12832032, from the Ministry of Education, Science, Sports, Culture and Technology of Japan.

References

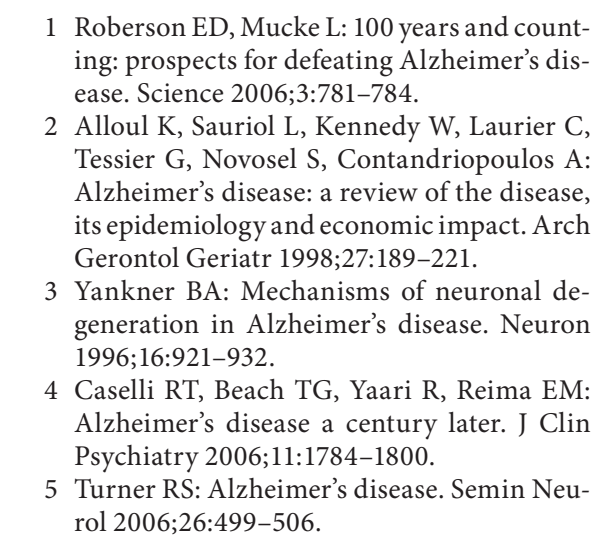

Wu/Sasaki/Yoshimoto/Kawahara/ Manabe/Kataoka/Asashima/Yuge 
6 Selkoe DJ: Alzheimer's disease: genes, proteins, and therapy. Physiol Rev 2001;81:741766.

7 Dahm R: Alzheimer's discovery. Curr Biol 2006;16:R906-R910.

8 LeBlanc AC: The role of apoptotic pathways in Alzheimer's disease neurodegeneration and cell death. Curr Alzheimer Res 2005;2: 389-402.

-9 Glenner GG, Wong CW: Alzheimer's disease: initial report of the purification and characterization of a novel cerebrovascular amyloid protein. Biochem Biophys Res Commun 1984;120:885-890.

10 Olesen OF: Tau, amyloid and Alzheimer's disease. Ugeskr Laeger 1994;156:1116-1117, 1121-1124.

-11 Pastorino L, Lu KP: Pathogenic mechanisms in Alzheimer's disease. Eur J Pharmacol 2006;545:29-38.

12 Billingsley ML, Kincaid RL: Regulated phosphorylation and dephosphorylation of tau protein: effects on microtubule interaction, intracellular trafficking and neurodegeneration. Biochem J 1997;323:577-591.

13 Ruben GC, Wang JZ, Iqbal K: Paired helical filaments (PHFs) are a family of single filament structures with a common helical turn period: negatively stained PHF imaged by TEM and measured before and after sonication, deglycosylation, and dephosphorylation. Microsc Res Tech 2005;67:175-195.

-14 Alafuzoff I, Iqbal K, Friden H, Adolfsson R, Winblad B: Histopathological criteria for progressive dementia disorders: clinicopathological correlation and classification by multivariate data analysis. Acta Neuropathol 1987;74:209-225.

-15 Dessi F, Colle MA, Hauw JJ, Duyckaerts C: Brain lesions, pathogenic and etiologic hypotheses of Alzheimer's disease. Rev Prat 1998;48:1873-1878.

-16 Gomez-Ramos A, Diaz-Hernandez M, Cuadros R, Hernandez F, Avila J: Extracellular tau is toxic to neuronal cells. FEBS Lett 2006;580:4842-4850.

17 Komblum HI: Introduction to neural stem cells. Stroke 2007;38:810-816.

18 Park KI, Himes BT, Stieg PE, Tessler A, Fischer I, Snyder EY: Neural stem cells may be uniquely suited for combined gene therapy and cell replacement: evidence from engraftment of neurotrophin-3-expressing stem cells in hypoxic-ischemic brain injury. Exp Neurol 2006;199:179-190.

19 Westerlund U, Moe MC, Varghese M, BergJohnsen J, Ohlsson M, Langmoen IA, Svensson M: Stem cells from the adult human brain develop into functional neurons in culture. Exp Cell Res 2003;289:378-383.

20 Jordan JD, Ming GL, Song H: Adult neurogenesis as a potential therapy for neurodegenerative diseases. Discov Med 2006;6: 144-147.
21 Reubinoff BE, Itsykson P, Turetsky T, Pera MF, Reinhartz E, Itzik A, Ben-Hur T: Neural progenitors from human embryonic stem cells. Nat Biotechnol 2001;19:1134-1140.

-22 Martínez-Serrano A, Fischer W, Söderström S, Ebendal T, Björklund A: Long-term functional recovery from age-induced spatial memory impairments by nerve growth factor (NGF) gene transfer to the rat basal forebrain. Proc Natl Acad Sci USA 1996;93: 6355-6360.

23 Lin LF, Doherty D, Lile J, Bektesh S, Collins F: GDNF: a glial cell line-derived neurotrophic factor for midbrain dopaminergic neurons. Science 1993;260:1130-1132.

24 Dunnett SB, Rosser AF: Stem cell transplantation for Huntington's disease. Exp Neurol 2007;203:279-292.

25 Kusano K, Tsutsumi Y, Dean J, Gavin M, Ma $\mathrm{H}$, Silver M, Thorne T, Zhu Y, Losordo DW, Aikawa R: Long-term stable expression of human growth hormone by rAAV promotes myocardial protection post-myocardial infarction. J Mol Cell Cardiol 2007;42:390399.

26 Paxinos G, Watson C: The Rat Brain in Stereotaxic Coordinates, ed 4. San Diego, Academic Press, 1998.

27 Morris R: Development of a water-maze procedure for studying spatial learning in the rat. J Neurosci Methods 1984;11:47-60.

28 Dickson DW, Wertkin A, Mattiace LA, Fier E, Kress Y, Davies P, Yen SH: Ubiquitin immunoelectron microscopy of dystrophic neurites in cerebellar senile plaques of Alzheimer's disease. Acta Neuropathol 1990;79: 486-493.

29 Carson F, Freida L: Histotechnology: A SelfInstructional Text. Chicago, American Society for Clinical Pathology, 1990, pp 167169.

30 Harris KA, Oyler GA, Doolittle GM, Vincent I, Lehman RA, Kincaid RL, Billingsley ML: Okadaic acid induces hyperphosphorylated forms of tau protein in human brain slices. Ann Neurol 1993;33:77-87.

31 Merrick SE, Trojanowski JQ, Lee VY: Selective destruction of stable microtubules and axons by inhibitors of protein serine/threonine phosphatases in cultured human neurons. J Neurosci 1997; 17:5726-5737.

32 Harotunia V, Davies P, Vianna C, Buxbaum JD, Purohit DP: Tau protein abnormalities associated with the progression of Alzheimer disease type dementia. Neurobiol Aging 2007;28:1-7.

33 Koss DJ, Hindley KP, Riedel G, Platt B: Modulation of hippocampal calcium signalling and plasticity by serine/threonine protein phosphatases. J Neurochem 2007;102:1009_ 1023.

34 Vogelsberg-Ragaglia V, Schuck T, Trojanowski JQ, Lee VM-Y: PP2A mRNA expression is quantitatively decreased in Alzheimer's disease hippocampus. Exp Neurol 2001;168:402-412.
35 Ha DH, Robertson RT, Roshanaei M, Weiss $\mathrm{JH}$ : Enhanced survival and morphological features of basal forebrain cholinergic neurons in vitro: role of neurotrophins and other potential cortically derived cholinergic trophic factors. J Comp Neurol 1999;406: 156-170.

36 Heese K, Low JW, Inoue H: Nerve growth factor, neural stem cells and Alzheimer's disease. Neurosignals 2006-2007;15:1-12.

37 Genciarelli C, Budoni M, Mercanti D, Fernandez E, Pallini R, Aloe L, Cimino V, Maira $G$, Casalbore P: In vitro analysis of mouse neural stem cells genetically modified to stably express human NGF by a novel multigenic viral expression system. Neurol Res 2006; 28:505-512.

-38 Ebert AD, Svendsen CN: A new tool in the battle against Alzheimer's disease and aging: ex vivo gene therapy. Rejuvenation Res 2005; 8:131-134.

39 Tuszynski MH: Growth-factor gene therapy for neurodegenerative disorders. Lancet Neurol 2002;1:51-57.

-40 Smith DE, Roberts J, Gage FH, Tuszynski $\mathrm{MH}$ : Age-associated neuronal atrophy occurs in the primate brain and is reversible by growth factor gene therapy. Proc Natl Acad Sci USA 1999;96:10893-10898.

41 Tuszynski MH, Roberts J, Senut MC, Gage FH: Gene therapy in the adult primate brain: intraparenchymal grafts of cells genetically modified to produce nerve growth factor prevent cholinergic neuronal degeneration. Gene Ther 1996;3:305-314.

42 Oliveira AA Jr, Hodges HM: Alzheimer's disease and neural transplantation as prospective cell therapy. Curr Alzheimer Res 2005;2: 79-95.

43 Pluchino S, Zanotti L, Deleidi M, Martino G: Neural stem cells and their use as therapeutic tool in neurological disorders. Brain Res Rev 2005;48:211-219.

44 Reimers D, Lopez-Toledano MA, Mason I, Cuevas P, Redondo C, Herranz AS, Lobo MV, Bazan E: Developmental expression of fibroblast growth factor (FGF) receptors in neural stem cell progeny: modulation of neuronal and glial lineages by basic FGF treatment. Neurol Res 2001;23:612-621.

$\checkmark 4$ Jori FP, Galderisi U, Piegari E, Cipollaro M, Cascino A, Pelaso G, Cotrufo R, Giordano A, Melore MA: EGF-responsive rat neural stem cells: molecular follow-up of neuron and astrocyte differentiation in vitro. J Cell Physiol 2003; 195:220-233.

46 Hardy J, Allsop D: Amyloid deposition as the central event in the etiology of Alzheimer's disease. Trends Pharmacol Sci 1991;12:383388.

-47 Oddo S, Vasilevko V, Caccamo A, Kitazawa M, Cribbs DH, LaFerla FM: Reduction of soluble Abeta and tau, but not soluble Abeta alone, ameliorates cognitive decline in transgenic mice with plaques and tangles. J Biol Chem 2006;281:39413-39423. 
-48 Sugaya K, Alvarez A, Marutle A, Kwak YD, Choumkina E: Stem cell strategies for Alzheimer's disease therapy. Panminerva Med 2006;48:87-96.

49 Oliveira AA Jr, Hodges HM: Alzheimer's disease and neural transplantation as prospective cell therapy. Curr Alzheimer Res 2005;2: 79-95.

50 Wang Q, Matsumoto Y, Shindo T, Miyake K, Shindo A, Kawanishi M, Kawai N, Tamiya T, Nagao S: Neural stem cells transplantation in cortex in a mouse model of Alzheimer's disease. J Med Invest 2006;53:61-69.
1 Rossi F, Cattaneo E: Opinion: neural stem cell therapy for neurological diseases: dreams and reality. Nat Rev Neurosci 2002;3:401409.

52 Nakatomi H, Kuriu T, Okabe S, Yamamoto S, Hatano O, Kawahara N, Tamura A, Kirino T, Nakafuku M: Regeneration of hippocampal pyramidal neurons after ischemic brain injury by recruitment of endogenous neural progenitors. Cell 2002;110:429-441.

53 Sugaya K, Brannen CL: Stem cell strategies for neuroreplacement therapy in Alzheimer's disease. Med Hypotheses 2001;57:697700 .
54 Williams LR: Exogenous nerve growth factor stimulates choline acetyltransferase activity in aging Fischer 344 male rats. Neurobiol Aging 1991;12:39-46.

55 Salehi A, Delcroix JD, Swaab DF: Alzheimer's disease and NGF signaling. J Neural Transm 2004;111:323-345.

56 Martinez-Serrano A, Björklund A: Ex vivo nerve growth factor gene transfer to the basal forebrain in presymptomatic middle-aged rats prevents the development of cholinergic neuron atrophy and cognitive impairment during aging. Proc Natl Acad Sci USA 1998; 95:1858-1863. 